\title{
Lewis Base Passivation Mediates Charge Transfer at Perovskite Heterojunctions
}

Robert J. E. Westbrook ${ }^{1,2,3}$, Thomas J. Macdonald ${ }^{1,3}$ Weidong $\mathrm{Xu}^{1,3}$, Luis Lanzetta ${ }^{1,3}$, Jose M. Marin-Beloqui, ${ }^{2}$ Tracey M. Clarke ${ }^{2}$, Saif A. Haque ${ }^{1,3 *}$

${ }^{1}$ Department of Chemistry, Imperial College London, Molecular Sciences Research Hub

White City Campus, Wood Lane, W12 0BZ, UK

${ }^{2}$ Department of Chemistry, University College London, 20 Gordon Street, London WC1H OAJ, UK

${ }^{3}$ Centre for Processable Electronics, Imperial College London, London SW7 2AZ, UK

*Corresponding author: S.A.H (s.a.haque@imperial.ac.uk)

Supporting Information: 
Table S1: Literature and averaged values for $\mathrm{MAPb}_{3}$ valence band and PTAA, PTPD and P3HT highest occupied molecular orbital (HOMO). For consistency, values were selected from photoelectron spectroscopy (PES) measurements only.

\begin{tabular}{ccccc}
\hline Desc. & $E_{1}(\mathrm{eV})$ & $E_{2}(\mathrm{eV})$ & $E_{3}(\mathrm{eV})$ & $\bar{E}(\mathrm{eV})$ \\
\hline MAPbl $_{3}$ & $5.5^{1}$ & $5.5^{2}$ & $5.4^{5}$ & 5.5 \\
PTAA & $5.1^{1}$ & $5.2^{2}$ & $5.2^{6}$ & 5.2 \\
PTPD & $5.3^{1}$ & $5.1^{3}$ & $5.3^{7}$ & 5.2 \\
P3HT & $5.1^{1}$ & $4.8^{4}$ & $5.2^{8}$ & 5.0 \\
\hline
\end{tabular}

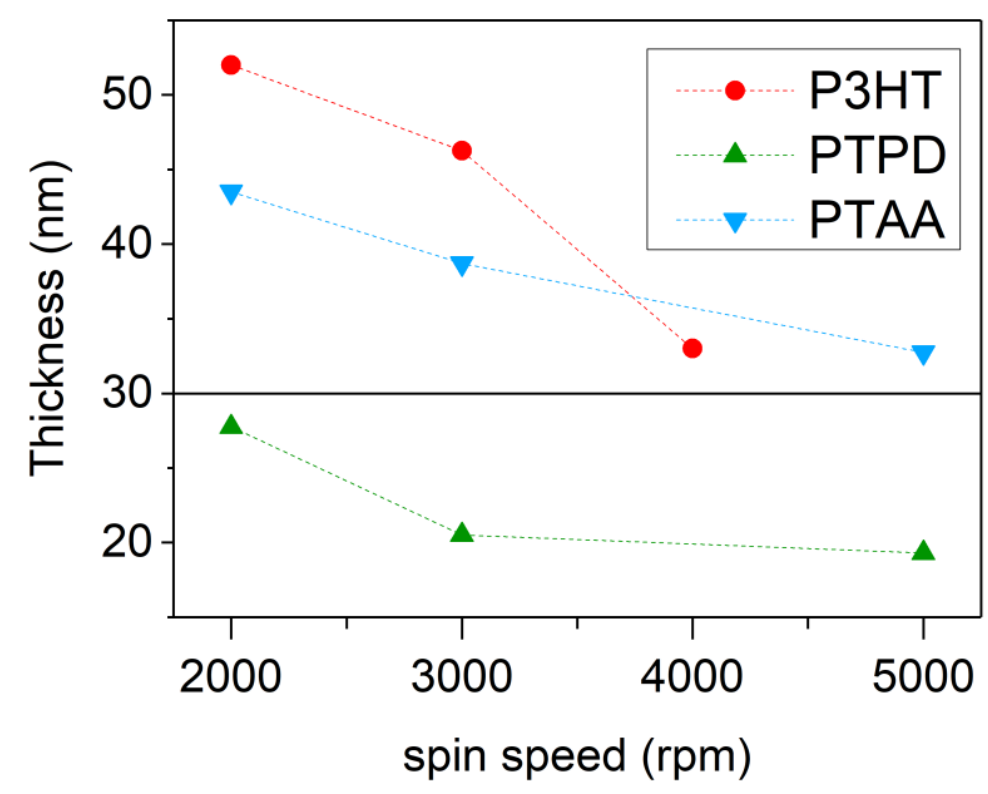

Fig S1: Thickness of P3HT, PTPD and PTAA layers at $10 \mathrm{mg} \mathrm{mL}^{-1}, 8 \mathrm{mg} \mathrm{mL}^{-1}$ and $10 \mathrm{mg} \mathrm{mL}^{-1}$ deposited on glass as a function of spin-speed, measured by DEKTAK.

Table S2: Optimised thickness and corresponding spin-coater rotation speed for the HTL films used in this work.

\begin{tabular}{lll}
\hline HTL & Spin speed $(\mathbf{r p m})$ & Thickness $(\mathbf{n m})$ \\
\hline PTAA & 5000 & 33 \\
PTPD & 2000 & 28 \\
P3HT & 4000 & 33 \\
\hline
\end{tabular}




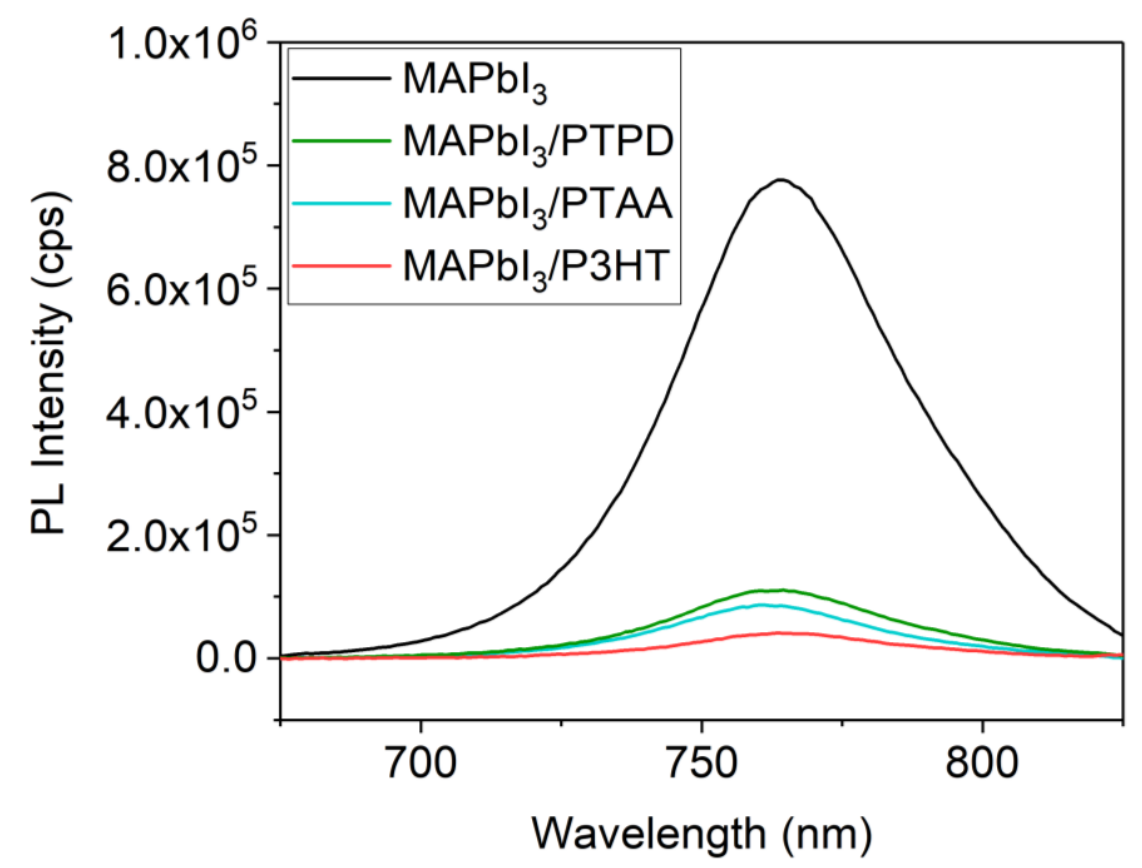

Fig S2: Raw steady-state photoluminescence spectra for $\mathrm{MAPb}_{3} / \mathrm{HTL}(\mathrm{HTL}=\mathrm{PTAA}, \mathrm{PTPD}, \mathrm{P} 3 \mathrm{HT})$ films.
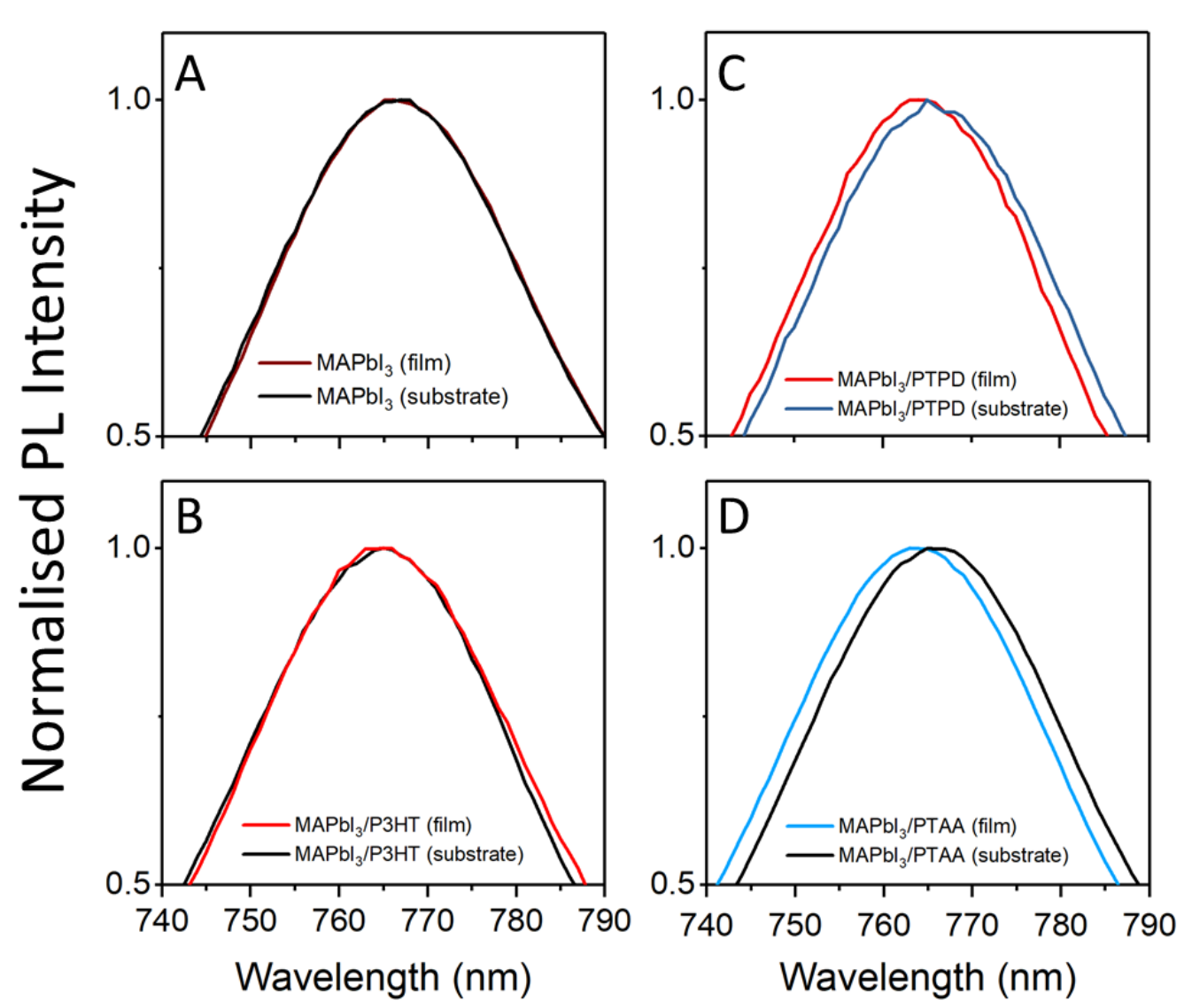

Fig S3: Normalised steady-state photoluminescence spectra for (a) $\mathrm{MAPb}_{3}$, (b) $\mathrm{MAPbl}_{3} / \mathrm{P3HT}$, (c) $\mathrm{MAPb}_{3} / \mathrm{PTPD}$ and (d) $\mathrm{MAPbl}_{3} / \mathrm{PTAA}$ films where the excitation was applied from the substrate/ $\mathrm{MAPbl}_{3}$ (black) and $\mathrm{MAPbl} / 3 / \mathrm{HTL}$ (coloured) interface. 


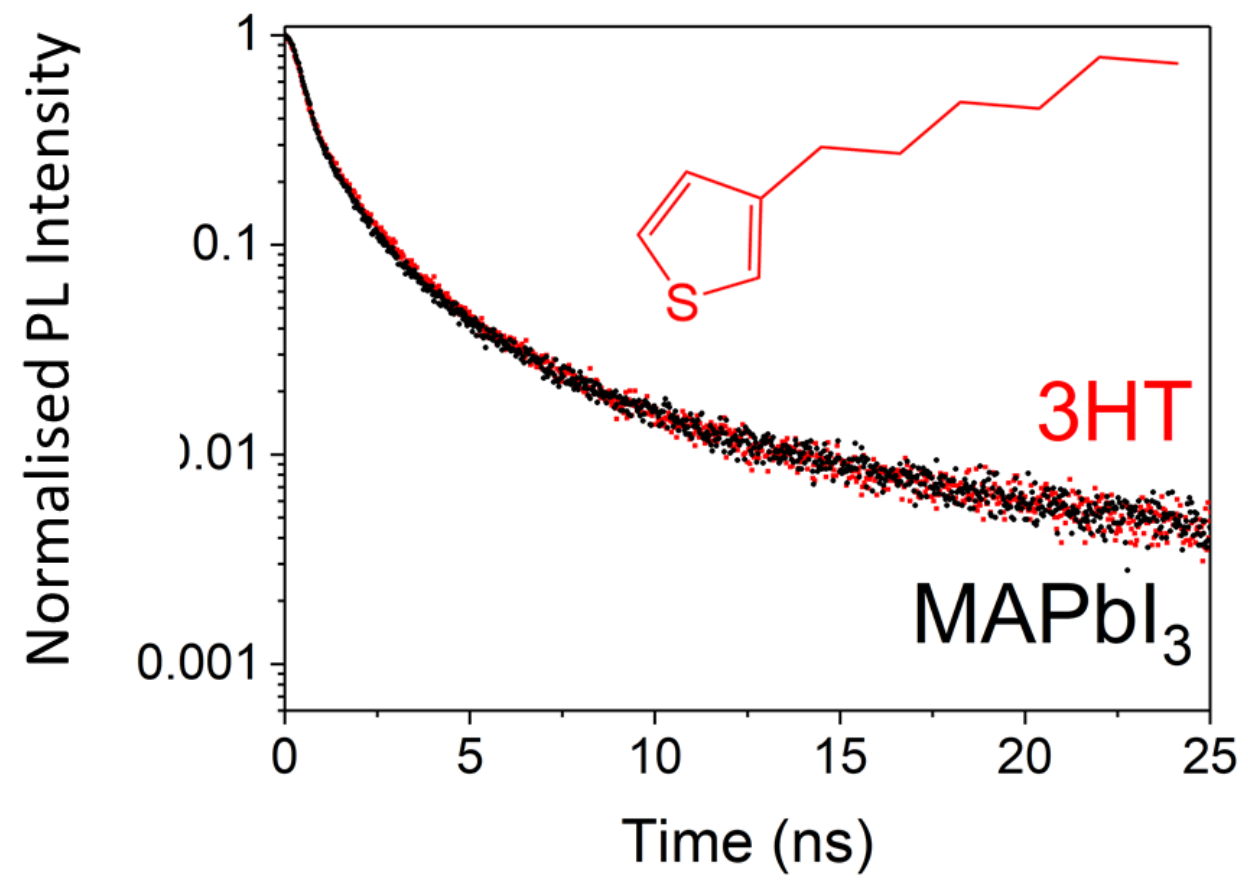

Fig S4: Comparison of the PL decay dynamics for $\mathrm{MAPbl}_{3}$ (black) and MAPbl $3: 3 \mathrm{HT}$ (red) films, measured via time-correlated single photon counting (TCSPC). Structure of $3 \mathrm{HT}$ is given in the inset. 


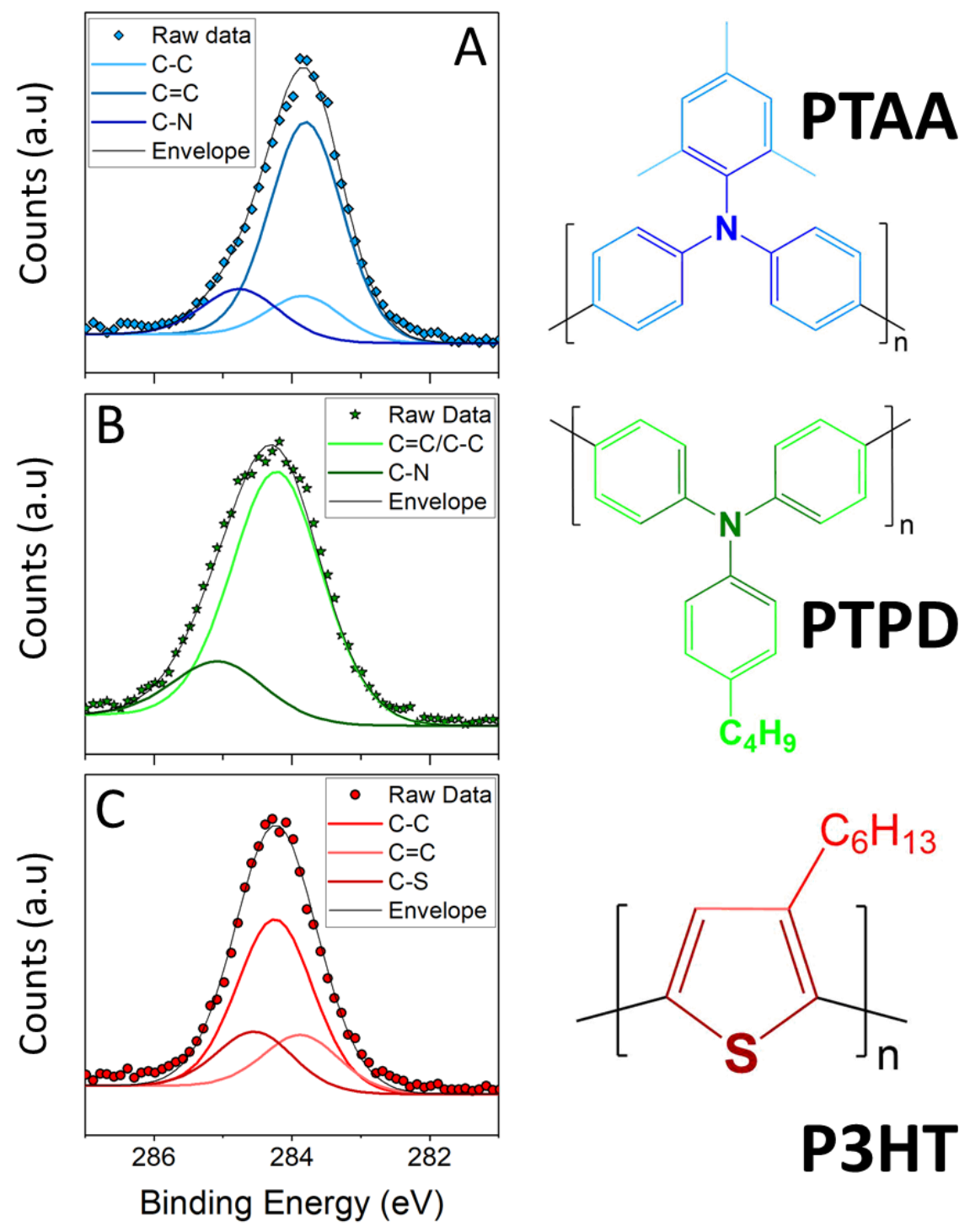

Fig S5: XPS spectra of $\mathrm{MAPbl}_{3} / \mathrm{HTL}$ (HTL = PTAA, PTPD, P3HT) films. C 1s spectra for (a) MAPbl 3 /PTAA, (b) $\mathrm{MAPbl}_{3} / \mathrm{PTPD}$ and (c) $\mathrm{MAPbl}_{3} / \mathrm{P} 3 \mathrm{HT}$. The deconvoluted peaks are colour coded and coordinated to the corresponding bonds in the polymer structures (right hand panel). 

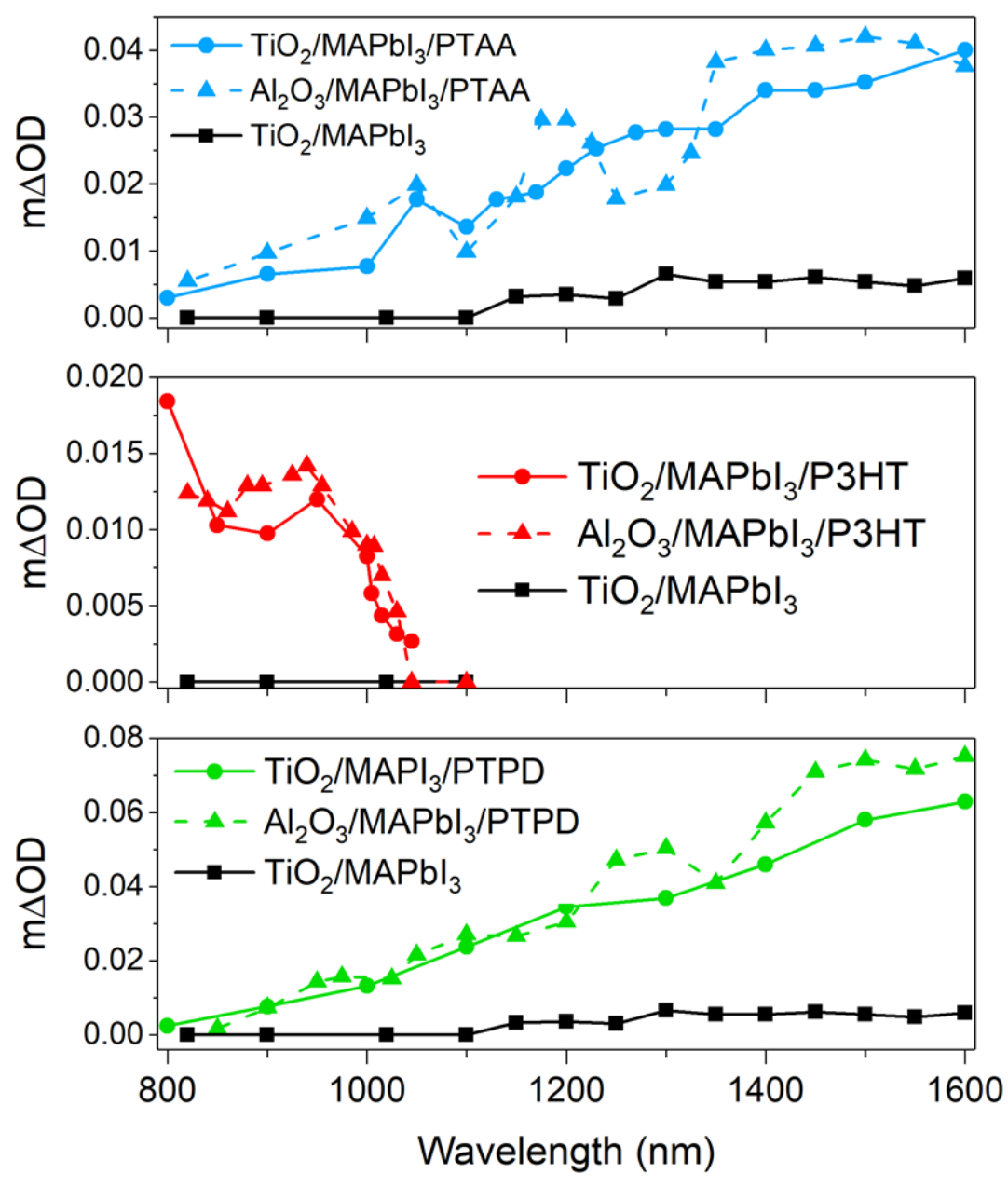

Fig S6: Transient absorption spectra of $\mathrm{CH}_{3} \mathrm{NH}_{3} \mathrm{Pbl}_{3} / \mathrm{HTL}$ ( $\mathrm{HTL}=\mathrm{PTAA}, \mathrm{P} 3 \mathrm{HT}$, PTPD) samples measured $1 \mu \mathrm{s}$ after excitation at $510 \mathrm{~nm}$. Polaron structures given in right-hand panel.

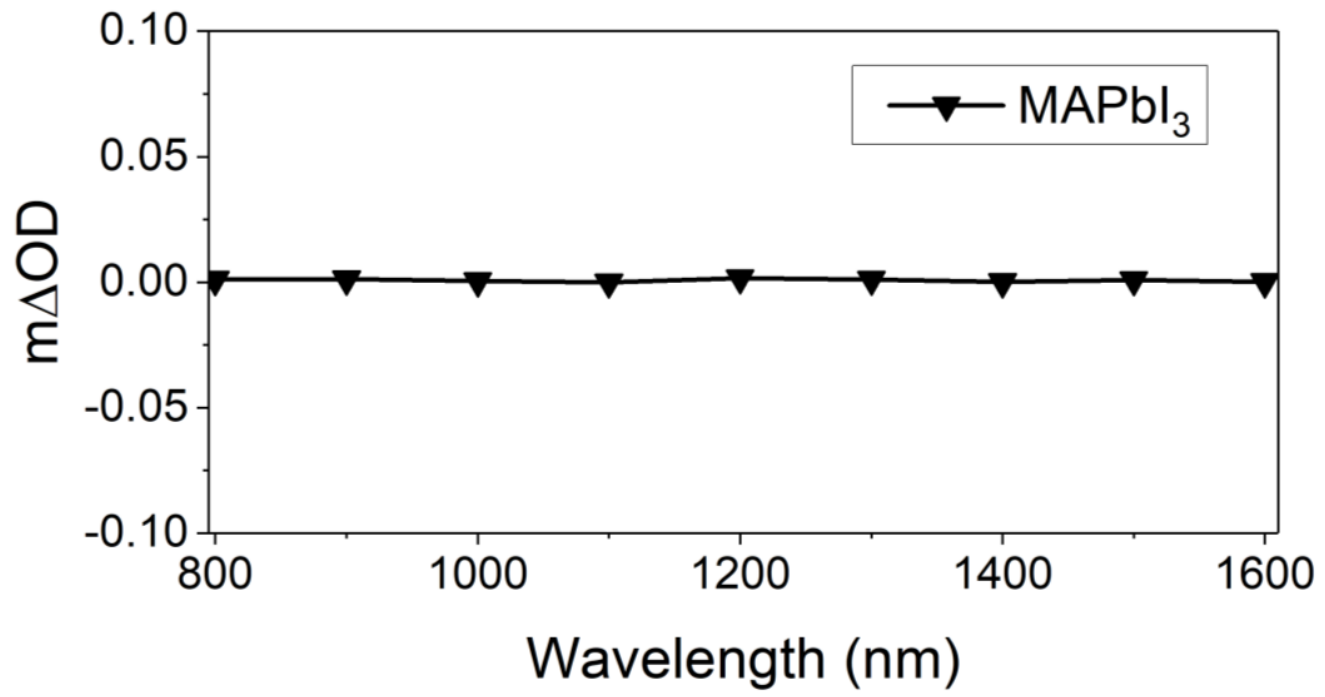

Fig S7: Transient absorption spectrum taken $1 \mu \mathrm{s}$ after excitation of a $\mathrm{CH}_{3} \mathrm{NH}_{3} \mathrm{Pbl}_{3}$ film at $510 \mathrm{~nm}$. 


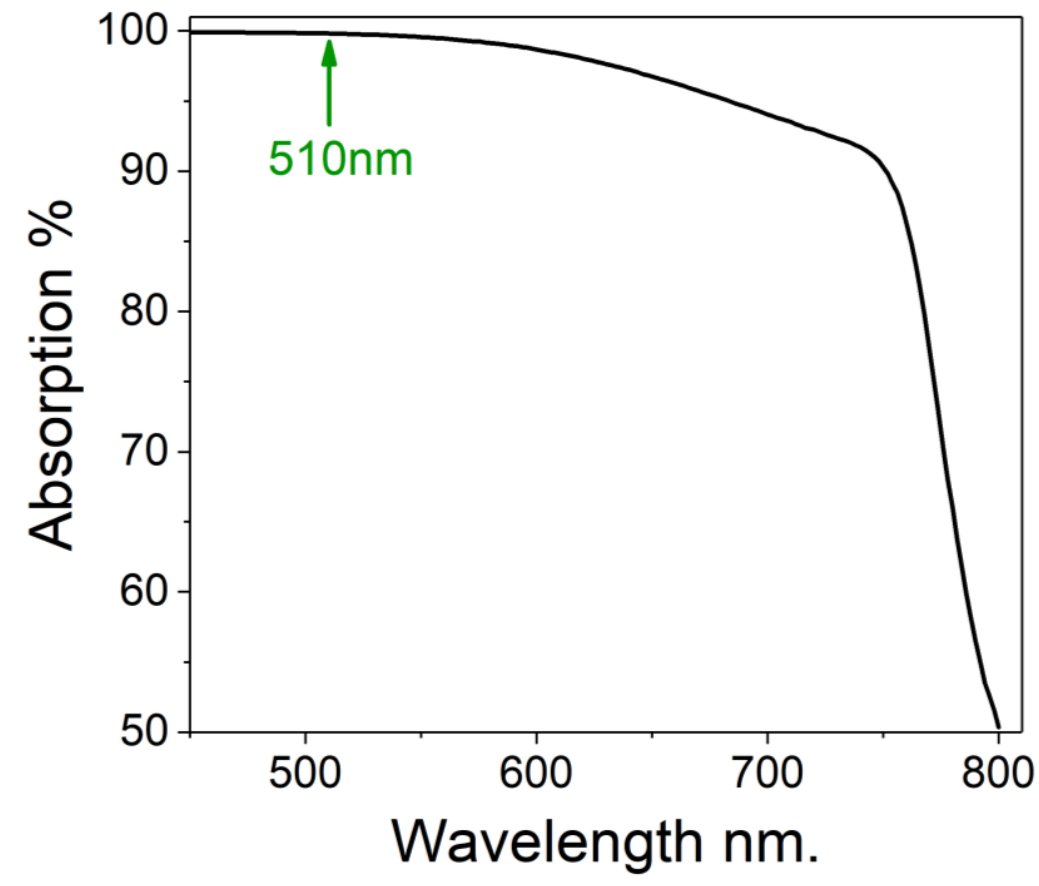

Fig S8: Absorption of $\mathrm{MAPbl}_{3}$ film measured as $A(\%)=100-T(\%)-R(\%)$, where $T$ and $R$ are the transmittance and reflectance respectively.

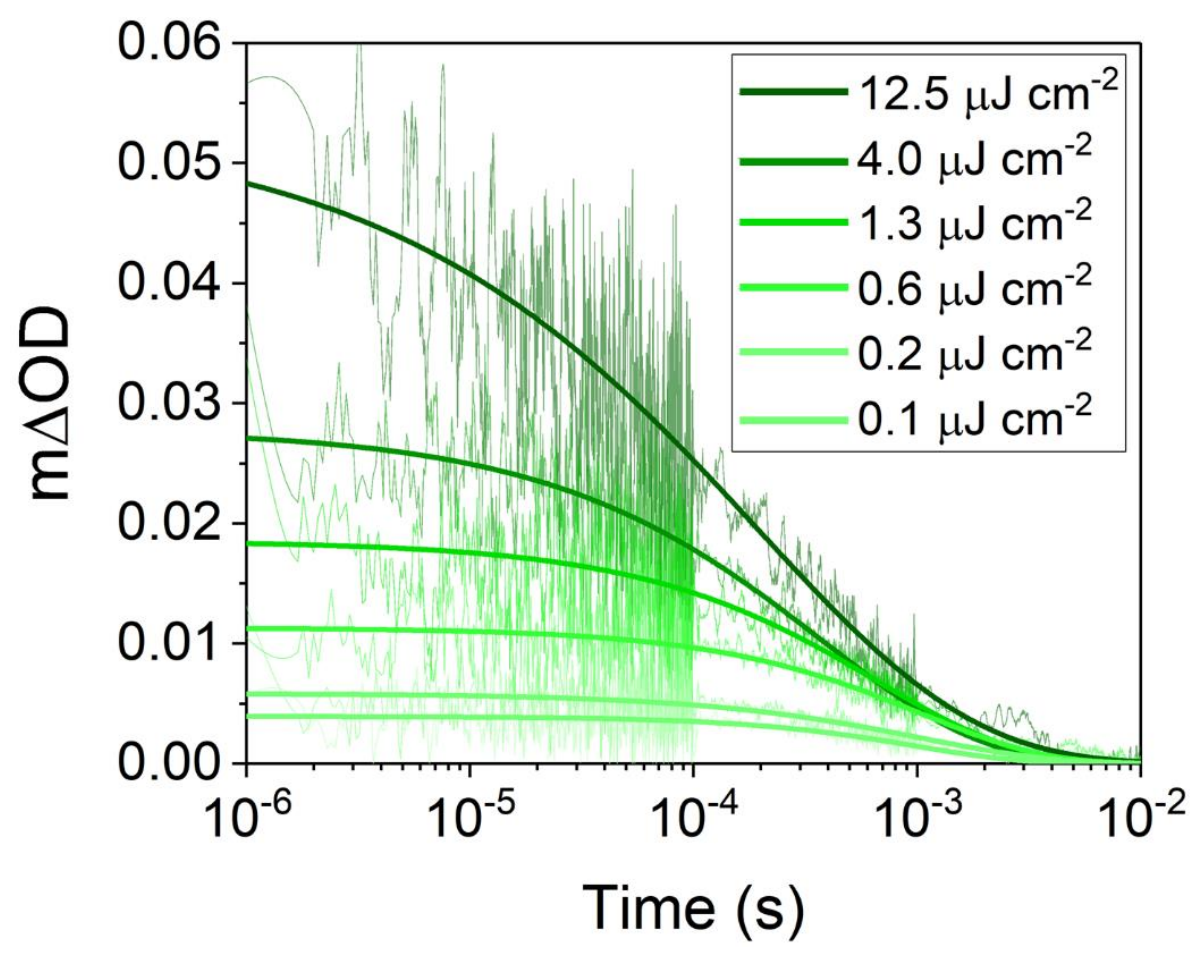

Fig S9: TAS traces for a $\mathrm{TiO}_{2}\left|\mathrm{MAPb}_{3}\right| \mathrm{PTPD}$ sample across the entire range of fluence covered in this study. For clarity, only half of the traces used for the analysis are shown, with alternating fluences omitted. 


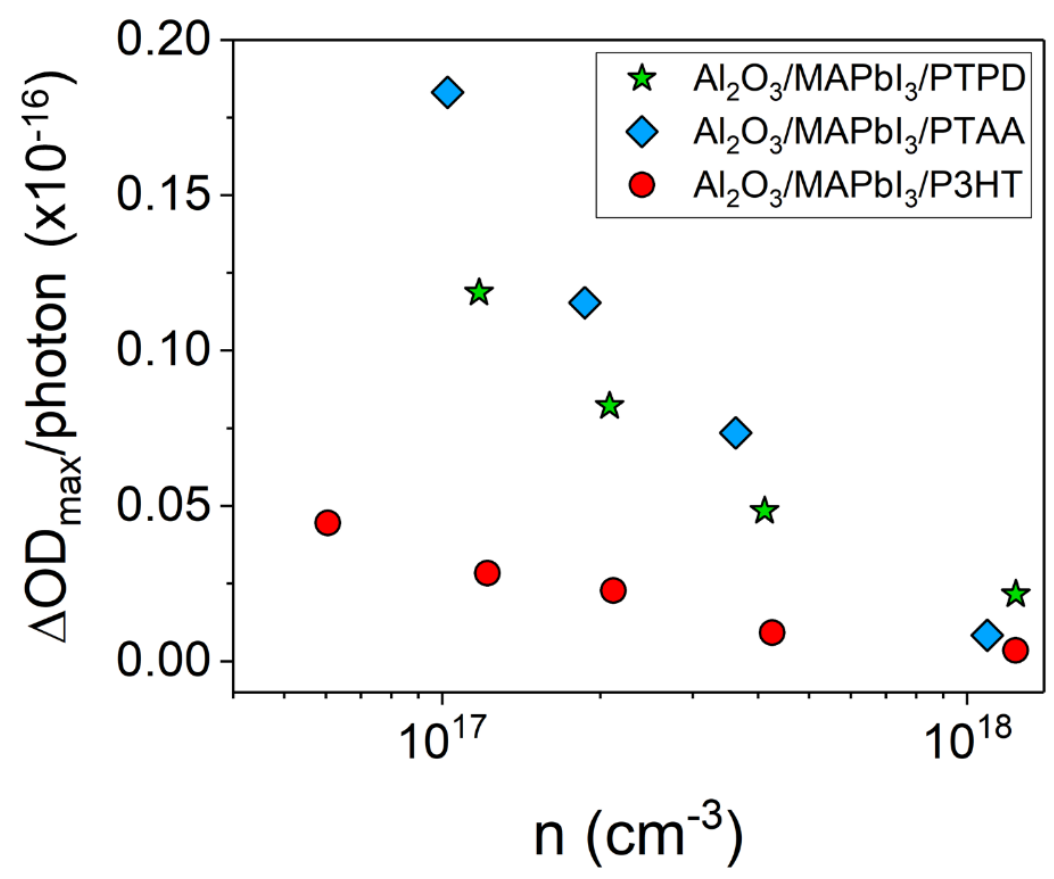

Fig S10: Relative hole injection yield, $\triangle O D_{\max }$, normalised to photons absorbed as a function of the initial carrier density, $n$ in the $\mathrm{MAPbl}_{3}$ layer for $\mathrm{Al}_{2} \mathrm{O}_{3} /\left.\mathrm{MAPb}\right|_{3} / \mathrm{HTL}$ (HTL = PTAA, PTPD, P3HT) films.

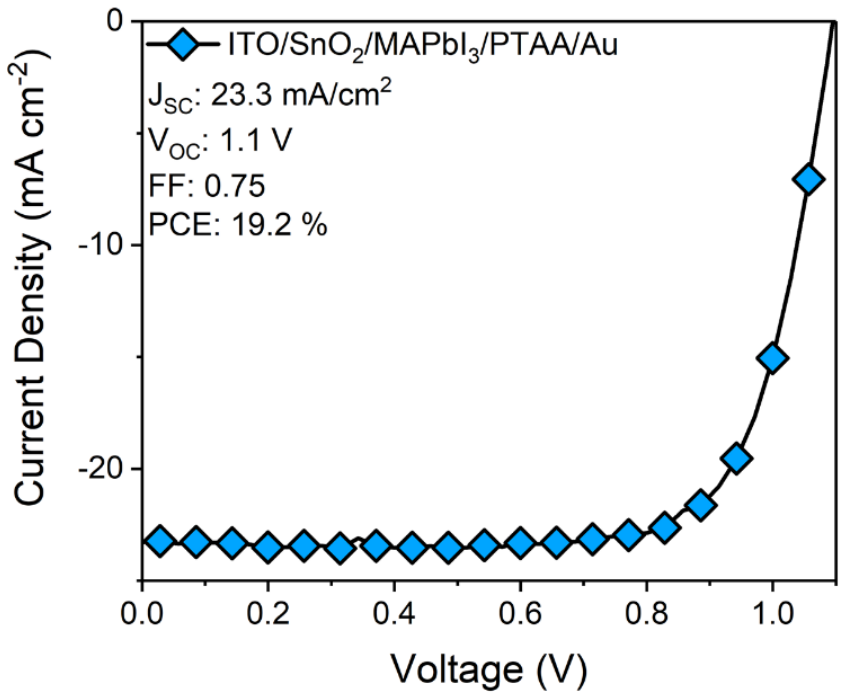

Fig S11: J-V characteristics of an ITO/SnO $/ \mathrm{MAPbI}_{3} / \mathrm{PTAA} / \mathrm{Au}$ device in which the PTAA is doped with $4 \mu \mathrm{L}$ of $170 \mathrm{mg} \mathrm{mL}^{-1} \mathrm{LiTFSI}$. 


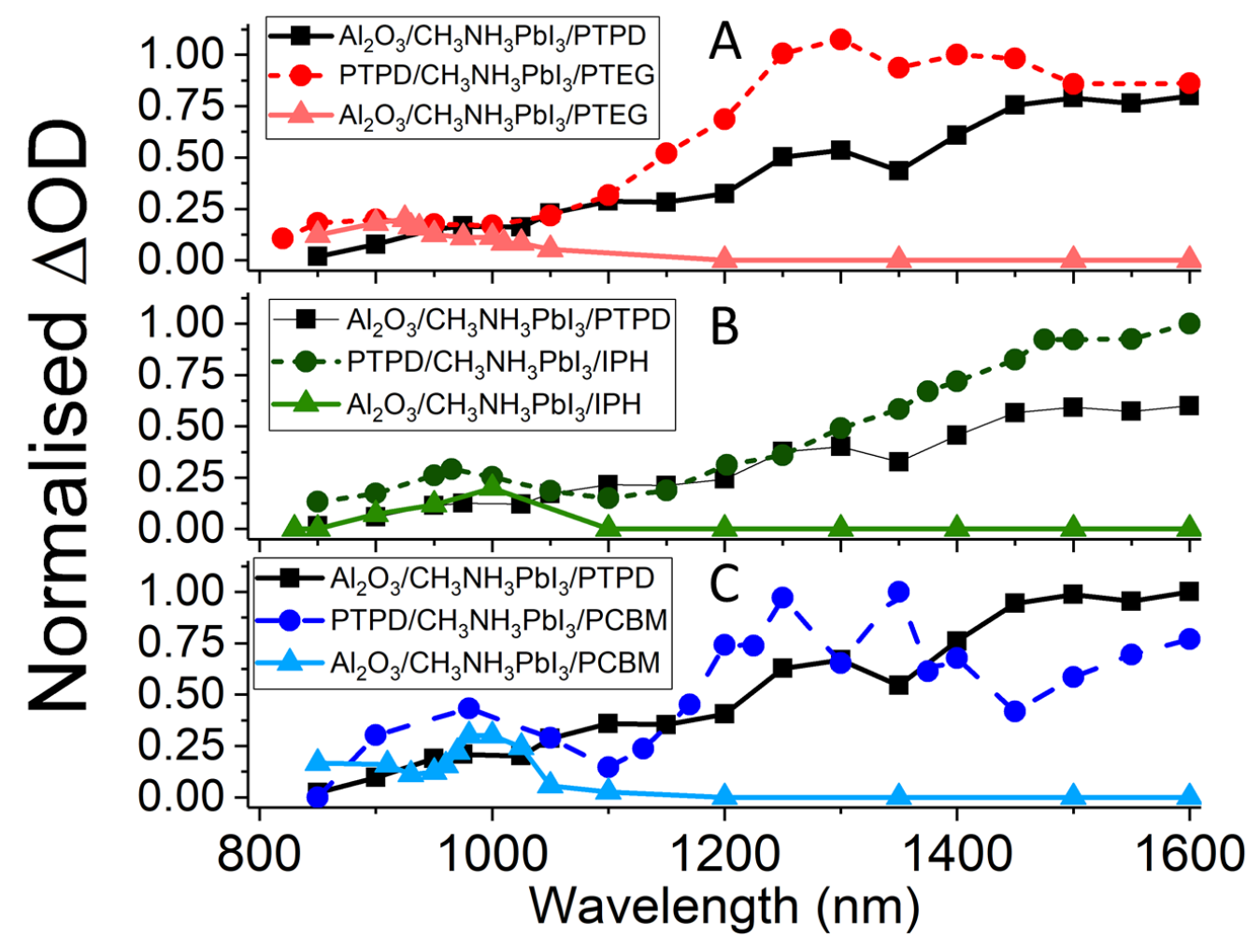

Fig S12: Normalised transient spectra taken at $1 \mu \mathrm{s}$ for PTPD/MAPbl $3 / \mathrm{ETL}$ and $\mathrm{Al}_{2} \mathrm{O}_{3} / \mathrm{MAPbl}_{3} / \mathrm{ETL}$ (ETL $=\mathrm{PCBM}, \mathrm{IPH}, \mathrm{PTEG}$ ) samples. $\mathrm{Al}_{2} \mathrm{O}_{3} / \mathrm{MAPbl}_{3} / \mathrm{PTPD}$ (black) is given in each figure.

\section{References}

1. M. Stolterfoht et al. The Impact of Energy Alignment and Interfacial Recombination on the Internal and External Open-Circuit Voltage of Perovskite Solar Cells. Energy Environ. Sci. 2019, 12, 2778-2788.

2. N. Ishida et al. Quantifying Hole Transfer Yield from Perovskite to Polymer Layer: Statistical Correlation of Solar Cell Outputs with Kinetic and Energetic Properties. ACS Photonics 2016, 3, 1678-1688

3. D. Kim et al. Efficiency enhancement of organic light-emitting devices due to a localized surface plasmonic resonance effect of poly(4-butylphenyl-diphenylamine):dodecanethiol functionalized $\mathrm{Au}$ nanocomposites. Optics Express 2015, 23, 11211

4. Q. An et al. Simultaneous Improvement in Short Circuit Current, Open Circuit Voltage, and Fill Factor of Polymer Solar Cells through Ternary Strategy. ACS Appl. Mater. Interfaces 2015, 7, 3691-3698

5. P Schulz et al. Interface energetics in organo-metal halide perovskite-based photovoltaic cells. Energy Environ. Sci., 2014, 7, 1377

6. J Endres et al. Electronic structure of the $\mathrm{CsPbBr3} /$ polytriarylamine (PTAA) system. J. Appl. Phys. 2017, 121,035304

7. L. Meng et al. Pure Formamidinium-Based Perovskite Light-Emitting Diodes with High Efficiency and Low Driving Voltage. Adv. Mater. 2017, 29, 1603826

8. K. Noori et al. Energy-level alignment and open-circuit voltage at graphene/polymer interfaces: theory and experiment. 2D Mater. 2016, 3, 015003 